\title{
Dental-Skeletal Dimensions in Growing Individuals with Variations in the Lower Facial Height
}

\author{
Carla ENOKI ${ }^{1}$ \\ Carlos de Souza TELLES ${ }^{2}$ \\ Mírian Aiko Nakane MATSUMOTO³ \\ ${ }^{1}$ Department of Orthodontics and ${ }^{2}$ Department of Pediatric Dentistry, Faculty of Dentistry, \\ Federal University of Rio de Janeiro, Rio de Janeiro, RJ, Brazil \\ ${ }^{3}$ Discipline of Orthodontics, Faculty of Dentistry of Ribeirão Preto, University of São Paulo, Ribeirão Preto, SP, Brazil
}

\begin{abstract}
The dental and skeletal dimensions of individuals with Class I skeletal pattern in puberty were compared. Eighty patients with Class I malocclusion were selected, independent of the vertical relations (overbite) of the incisors. The sample was divided into 3 groups: normal, short and excessive lower anterior face height, based on facial proportions. The dental and skeletal measurements of the 3 groups were compared among themselves. In the angular measurements, the results showed no correlation in the mandibular plane angle. In the linear measurements, the mandibular length was significantly greater in the group of patients with short lower anterior face height, with a positive correlation among the three groups. The dentoalveolar heights of the incisors had a positive correlation among the three groups in relation to the lower anterior face height, showing that they are responsible for its variation.
\end{abstract}

Key Words: cephalometry, growth, lower facial height, facial types.

\section{INTRODUCTION}

The description of the dentofacial relationship of people with normal and abnormal facial morphology is one of the most common subjects in orthodontic literature (1-5). Due to the large variation that exists in the population, many studies have been made to describe the variations of the human face, including a system that identifies the various facial types. This classification is of great importance in the diagnosis and treatment planning of craniofacial and dental discrepancies (6).

Tsunori et al. (7) reported that facial type (short, average and long faces) in relation to morphological characteristics is an important factor to be considered in orthodontic treatment, because facial type influences growth prediction of the maxillofacial system in the anchorage system that is used during treatment for the goals of orthodontic treatment.

Facial proportions, as well as their height, once defined, stay constant throughout the life of the individual. Ligthelm-Bakker et al. (8) found a negative correlation between the average growth rate of the upper anterior face height with the lower anterior face height, suggesting that some children show accelerated growth in the lower face height, in relation to upper face height, and vice versa.

The effect of orthodontic treatment on the lower face height (ANS-Me) is a factor of great importance, to be confirmed by the orthodontist. However, the facial type should be considered when planning treatment, with or without extraction. In 1993, Chua et al. (9) used the lower anterior face proportion to demonstrate that nonextraction treatment showed downward and backward rotation of the mandible and an increased lower face height. On the other hand, extraction treatment is not associated with changes in the ANS-Me measurements.

Janson et al. (10) confirmed that the anterior face proportion is an instrument that could be used in the orthodontic diagnosis, instead of using only numerical vertical measurements.

The literature is in agreement with Creekmore (11) that any one technique or philosophy of treatment 
is inadequate, when used without consideration of the facial type of the patient. The vertical growth should be stimulated or inhibited i.e., redirected according to the needs of the individual patient. Thus, the importance of knowledge of facial types and their characteristics in relation to the growth pattern is clear.

The purpose of the present study was: a) to compare the maxillomandibular dimensions and inclinations, dental inclinations and dentoalveolar heights in patients with short, normal and excessive lower anterior face height; b) to determine the anatomical parts that may be responsible for the variation of the lower anterior face height.

\section{MATERIAL AND METHODS}

Pretreatment lateral cephalographs of eighty patients (11-13 years old) were analyzed from the files of

Table 1. Cephalometric landmarks used in this study.

\begin{tabular}{|c|c|c|}
\hline S & Sella & Center of sella turcica \\
\hline $\mathrm{N}$ & Nasion & Anterior point on the frontonasal suture \\
\hline A & Point A & $\begin{array}{l}\text { Deepest point on the concave outline of the } \\
\text { upper labial alveloar process }\end{array}$ \\
\hline$A^{\prime}$ & Point A' & Perpendicular from point A to palatal plane \\
\hline ANS & Anterior Nasal Spine & The tip of the anterior nasal spine \\
\hline PNS & Posterior Nasal Spine & The tip of the posterior nasal spine \\
\hline Is & Point Is & Maxillary incisal edge \\
\hline Ii & Point Ii & Mandibular incisal edge \\
\hline $6 s$ & Point $6 \mathrm{~s}$ & Mesiobuccal cusp of the upper first molar \\
\hline $6 \mathrm{i}$ & Point $6 \mathrm{i}$ & Mesiobuccal cusp of the lower first molar \\
\hline Pog & Pogonion & $\begin{array}{l}\text { The most anterior point on the mandibular } \\
\text { symphysis }\end{array}$ \\
\hline B & Point B & $\begin{array}{l}\text { The deepest point on the bony curvature } \\
\text { between the crest of the alveolus and the Pog }\end{array}$ \\
\hline $\mathrm{Me}$ & Menton & $\begin{array}{l}\text { The lowest point on the lower border of the } \\
\text { mandibular symphysis }\end{array}$ \\
\hline Go & Gonion & The midpoint at the angle of the mandible \\
\hline $\operatorname{Ar}$ & Articulare & $\begin{array}{l}\text { Intersection of the lateral radiographic image of } \\
\text { the posterior border of the ramus with the occipital bone }\end{array}$ \\
\hline Gn & Gnathion & $\begin{array}{l}\text { The most anterior-inferior point on the mandibular } \\
\text { symphysis }\end{array}$ \\
\hline Ptm & Pteryo maxillary fissure & Pteryo maxillary fissure \\
\hline Ptm' & Point Ptm' & $\begin{array}{l}\text { Perpendicular from pterygo maxillary fissure to } \\
\text { palatal plane }\end{array}$ \\
\hline
\end{tabular}

the Dental School Clinic at the Faculty of Dentistry, Federal University of Rio de Janeiro. All subjects had a skeletal pattern of Class I (ANB - $0^{\circ}$ to $4^{\circ}$ ) and presented dental standards of normality, with no anomalies or tooth loss that could interfere in the lower anterior face. The cephalometric landmarks used in this study are defined in Table 1. The angular and linear measurements were made in the cephalograms as described in Figures 1 and 2.

The patients were then divided into 3 groups according to facial third proportions obtained by linear measurements of the upper anterior face height $(\mathrm{N}$ ANS) and lower anterior face height (ANS-Me) based on the measurements suggested by Wylie and Johnson (1) with the proportion of $45 \%$ for N-ANS distance and $55 \%$ for ANS-Me distance. Using the standard deviation criterion suggested by Chang et al. (12), ANS-Me values were defined ranging from $54 \%$ to $56 \%$ for the normal lower anterior face height group, values smaller than $54 \%$ for the short lower anterior face height group, and values greater than $56 \%$ for the excessive lower anterior face height group. Consequently, the groups were composed of 20 patients in the short lower anterior face height group, 30 patients in the normal lower anterior face height group, and 30 patients in the excessive lower anterior face height group.

\section{Statistical Analysis}

The Kruskall-Wallis test was used to compare the dental and skeletal cephalometric measurements among the three groups studied. For the measurements that were significant $(\mathrm{p}<0.05)$, the MannWhitney test was used to determine between which group the differences were statistically significant. Pearson correlation coefficients were calculated to assess correlation between the lower anterior face height with each cephalometric measurement. Reliability degree ob- 
tained by operator was 92 percent.

\section{RESULTS}

The means, standard deviations, and significant differences $(\mathrm{p}<0.05)$ between the groups with short, normal and excessive lower anterior face height are reported for skeletal and dental measurements in Table 2.

There were no significant differences in skeletal

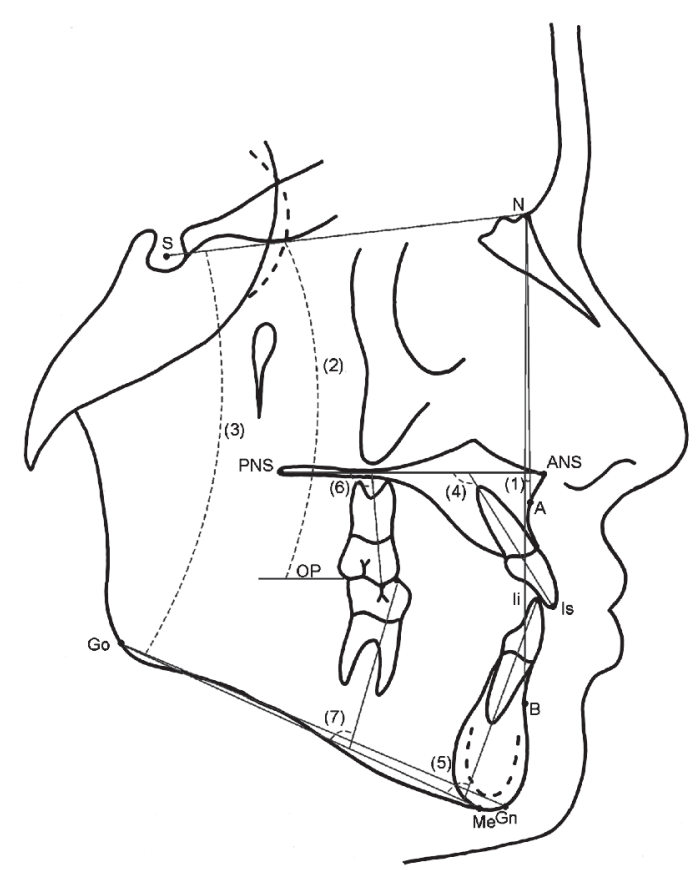

Figure 1. Tracing illustrating anatomic landmarks, points and angles of the dental and skeletal angular measurements used in this study.

(1) ANB: angle formed by the intersection of SN and NB.

(2) SN.OP: angle formed by the intersection of $\mathrm{SN}$ and the occlusal plane.

(3) SN.GoGn: angle formed by the inclination of the mandibular plane (Go-Gn) in relation to the anterior base of the cranium (SN).

(4) Is.PP: angular measure formed by the intersection of the maxillary incisors in relation to the palatal plane.

(5) Ii.MP: angular measure formed by the intersection of the mandibular incisors in relation to the mandibular plane.

(6) 6s.PP: angular measure formed by the intersection of the maxillary first molar in relation to the palatal plane.

(7) 6i.MP: angular measure formed by the intersection of the mandibular first molar in relation to the mandibular plane. measurements among the three groups with reference to the inclinations of the occlusal and mandibular planes in relation to the anterior base of the skull (SN.OP and SN.GoGn), ramus height (Ar-Go) and maxillary length (A'-Ptm').

There was a significant statistical difference in the mandibular length (Go-Pog) ( $<<0.01$; Mann-Whitney test) confirming that the mandibular length was larger in the short lower anterior face height when compared

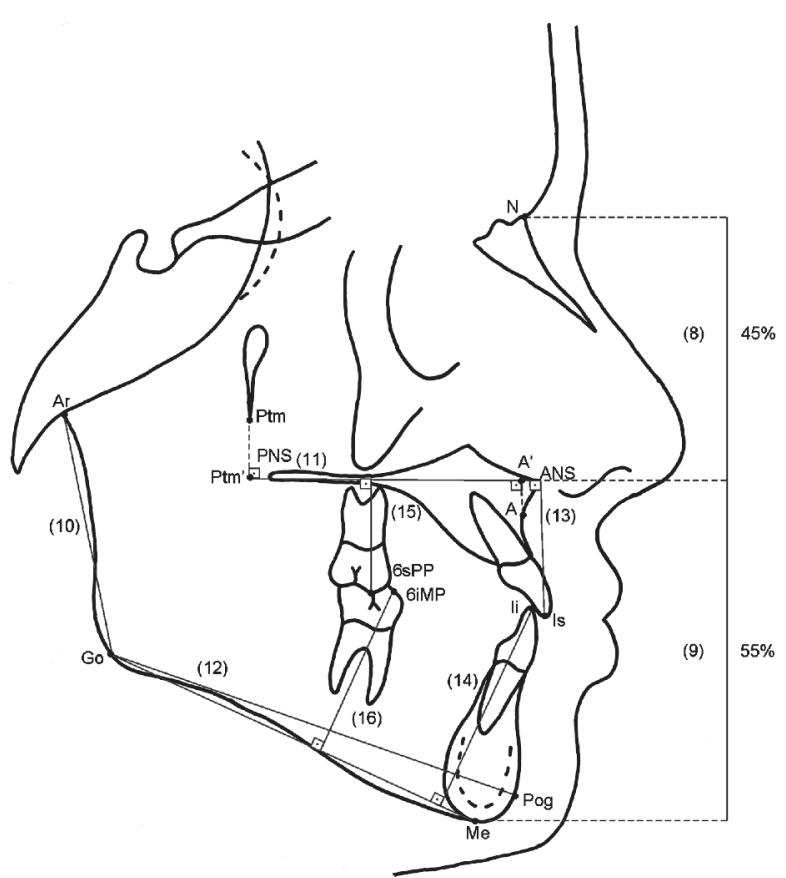

Figure 2. Tracing illustrating anatomic landmarks, points and angles of the dental and skeletal linear measurements used in this study.

(8) N-ANS: upper anterior face height $-\mathrm{N}$ to ANS.

(9) ANS-Me: lower anterior face height - ANS to Me.

(10) Ar-Go: rami height.

(11) A'-Ptm': maxillary length.

(12) Go-Pog: mandibular length.

(13) AUDH (anterior upper dentoalveolar height): linear distance from the incisal edge of the maxillary central incisor along a perpendicular to the palatal plane.

(14) ALDH (anterior lower dentoalveolar height): linear distance from the incisal edge of the mandibular central incisor along a perpendicular to the mandibular plane.

(15) 6s-PP (posterior maxillary dentoalveolar height): height of the maxillary first molar measured as a perpendicular to the palatal plane through the mesiobuccal cusp.

(16) 6i-MP (posterior mandibular dentoalveolar height): height of the mandibular first molar measured as a perpendicular to the mandibular plane through the mesiobuccal cusp. 
with the normal lower anterior face height (Table 3).

There were no significant differences in dental measurements between axial inclinations of the upper and the lower incisors compared to the palatal and mandibular planes, respectively, Is.PP and Ii.PM. On the other hand, the axial inclinations of the upper and lower permanent first molars in relation to the palatal (6s.PP) and mandibular (6i.PM) planes were greater in the short lower anterior face height group.

The dentoalveolar height in the superior incisor region (AUDH) was significantly greater in the excessive lower anterior face height group. However, in the lower incisor region (ALDH), the dentoalveolar height was smaller in the short lower anterior face height

Table 2. Comparison of the groups with normal, short, and excessive lower anterior face height.

\begin{tabular}{|c|c|c|c|c|c|c|c|}
\hline & \multicolumn{2}{|c|}{ Short } & \multicolumn{2}{|c|}{ Normal } & \multicolumn{2}{|c|}{ Excessive } & \multirow[t]{2}{*}{$\mathrm{z}$ value } \\
\hline & Mean & SD & Mean & SD & Mean & SD & \\
\hline PP.MP & 24.05 & & & 3.55 & 30.96 & 4.36 & $0.000 * *$ \\
\hline N-ANS & 54.65 & 2.08 & 52.36 & 3.03 & 50.20 & 2.44 & $0.000 * *$ \\
\hline ANS-Me & 61.20 & 2.85 & 64.26 & 3.38 & 67.93 & 4.79 & $0.000 * *$ \\
\hline Go-Pog & 78.30 & 4.18 & 74.63 & 5.08 & 75.36 & 5.44 & $0.043 *$ \\
\hline 6s.PP & 84.75 & 5.63 & 80.50 & 5.90 & 78.73 & 6.40 & $0.005^{* *}$ \\
\hline 6i.MP & 88.05 & 7.08 & 83.23 & 4.80 & 83.33 & 6.46 & $0.039 *$ \\
\hline Is-PP & 26.60 & 2.50 & 27.66 & 1.58 & 29.23 & 2.58 & $0.002 * *$ \\
\hline Ii-MP & 38.50 & 1.98 & 40.10 & 2.49 & 41.06 & 3.00 & $0.006 * *$ \\
\hline
\end{tabular}

$* \mathrm{p}<0.05 ; * * \mathrm{p}<0.001$ (Kruskall-Wallis test).

Table 3. Comparison of the measurements in normal, short and excessive lower anterior face height with significant $\mathrm{z}$ value in the Kruskall-Wallis test.

\begin{tabular}{|c|c|c|c|c|}
\hline \multirow[b]{3}{*}{ PP.MP } & \multirow{2}{*}{\multicolumn{2}{|c|}{$\frac{\text { Normal - Short }}{\text { z value }}$}} & \multirow{2}{*}{\multicolumn{2}{|c|}{$\frac{\text { Normal - Excessive }}{\text { z value }}$}} \\
\hline & & & & \\
\hline & 0.000 & $* *$ & 0.070 & ns \\
\hline 6s.PP & 0.009 & $* *$ & 0.563 & ns \\
\hline 6i.MP & 0.023 & $*$ & 0.882 & ns \\
\hline Go-Pog & 0.013 & $*$ & 0.548 & ns \\
\hline N-ANS & 0.002 & $* *$ & 0.100 & ns \\
\hline ANS-Me & 0.002 & $* *$ & 0.001 & $* *$ \\
\hline Is-PP & 0.077 & ns & 0.019 & $*$ \\
\hline Ii-MP & 0.027 & $*$ & 0.192 & $\mathrm{~ns}$ \\
\hline
\end{tabular}

${ }^{*} \mathrm{p}<0.05 ; * * \mathrm{p}<0.001 ; \mathrm{ns}=$ not significant. group when compared to the normal anterior face height group.

In the molar region (6s-PP and 6i-PM), there were no statistical differences among dentoalveolar heights in the three groups studied.

The Pearson correlation test indicated correlation between lower face height (ANS-Me) to the mandibular length (Go-Pog) and dentoalveolar height in the upper and lower incisor regions (AUDH and ALDH), in the three groups studied (Table 4).

\section{DISCUSSION}

The vertical facial growth pattern is a very important factor to consider in orthodontic treatment, especially with reference to the dental and skeletal characteristics of facial types in relation to the lower face height.

\section{Comparison of Skeletal Angular Measurements}

In the present study, there were no significant differences of the SN.MP angle among the groups. In long faces, according to Fields et al. (4), the total anterior facial height and the angle of the mandibular plane (SN.MP) are significantly larger than in normal faces. In short faces, the reverse is true. On the other hand, Opdebeeck and Bell (3) reported that a short face was not necessarily associated with a reduced SN-MP. Some persons within the clinical short face group manifested a normal SN.MP angle, combined, however, with a short rami. This implies

Table 4. Pearson Correlation for normal, short and excessive lower anterior face height group in relation of ANS-Me linear measurement.

\begin{tabular}{|c|c|c|c|c|c|c|}
\hline & \multicolumn{2}{|c|}{ Short } & \multicolumn{2}{|c|}{ Normal } & \multicolumn{2}{|c|}{ Excessive } \\
\hline & \multicolumn{2}{|c|}{$\mathrm{z}$ value } & \multicolumn{2}{|c|}{ z value } & \multicolumn{2}{|c|}{$\mathrm{z}$ value } \\
\hline ANS-Me x PP.MP & 0.068 & ns & 0.000 & $* *$ & 0.000 & $* *$ \\
\hline ANS-Me x Go-Pog & 0.000 & $* *$ & 0.004 & $* *$ & 0.006 & $* *$ \\
\hline ANS-Me x N-ANS & 0.025 & $*$ & 0.000 & $* *$ & 0.000 & $* *$ \\
\hline ANS-Me x Is-PP & 0.000 & $* *$ & 0.001 & $* *$ & 0.000 & $* *$ \\
\hline ANS-Me x Ii-MP & 0.000 & $* *$ & 0.000 & $* *$ & 0.000 & $* *$ \\
\hline ANS-Me x 6s-PP & 0.070 & ns & 0.000 & $* *$ & 0.000 & $* *$ \\
\hline ANS-Me x 6i-MP & 0.000 & $* *$ & 0.093 & ns & 0.000 & $* *$ \\
\hline
\end{tabular}

$* \mathrm{p}<0.05 ; * * \mathrm{p}<0.001 ; \mathrm{ns}=$ not significant. 
that the SN.MP angle cannot be the sole criterion in the selection and diagnosis of short face $(13,14)$.

Comparing the average of the PP.MP (palatal plane - mandibular plane) measurements (Table 2), there were significant differences $(\mathrm{p}<0.001)$ among the 3 groups. Comparing the groups 2 by 2 , differences were observed among the groups with normal and short lower anterior face height. Because the SN.MP measurements presented no significant differences among the 3 groups and, considering the base of the cranium (SN), a stable reference plane, not having significant variations of the mandibular plane in relation to the $\mathrm{SN}$ plane, it can be concluded that differences in the PP.PM measurements can be attributed to the palatal plane. The values of the PP.MP measurement in the 3 groups are responsible for the determination and division of the groups in to short, normal and excessive lower anterior face height, i.e., the location of the ANS point is directly responsible for the definition of the groups in this study.

It was observed that the angular PP.MP measurement presented a positive correlation in relation to the lower face height (ANS-Me) in the normal and excessive lower anterior face height groups, indicating that, when that value was increased, the tendency of the increase in the lower anterior face height was greater. However, in relation to the angle formed by the SN.OP, there were no significant differences among the groups, in agreement with the findings of Nanda (15).

\section{Comparison of the Dental Angular Measurements}

The axial inclinations of the upper and lower central incisors of the present study showed no significant differences ( $p>0.05)$, in contrast to the findings of Opdebeeck and Bell (3) and Opdebeeck et al. (16) who observed more accentuated dental axial inclinations in the group with short faces than in the group with long faces, suggesting a more upright position of the incisors in the short face group.

The inclinations of the permanent first molars on the left side in the mesiodistal direction presented significant differences among the 3 groups for the maxillary first molar $(\mathrm{p}<0.001)$ and for the mandibular first molar $(\mathrm{p}<0.05)$. The Mann-Whitney test (Table 3 ) indicated that these results are caused by the differences found between normal and short lower anterior face height groups. It showed significant inclination to the mesial of the crown of the first molars in the short lower anterior face height group.

\section{Comparison of the Skeletal Linear Measurements}

According to Bishara and Jakobsen (6), the mandibular length (Ar-Pog) presented no significant differences among the 3 facial types. Opdebeeck et al. (16) also found no significant differences in the maxillary and mandibular length among the groups with long and short faces and reported findings that suggest more retrusive positioning of the maxilla in the group with long faces. In the present study, there was no significant difference in the maxillary length (A'-Ptm'). However, there were differences among the groups with normal and short lower anterior face height for mandibular length (Go-Pog). A positive correlation (Table 4) was found in the 3 groups, indicating that, as these measurements were increased, the tendency of the lower anterior face height to be increased was greater.

Opdebeeck et al. (16) verified that, in the presence of short rami, reduction of the total posterior facial height in the patients with long faces occurs when compared to the short faces. In this study, the height of the mandibular rami was not significantly different among the groups, demonstrating that this linear measurement does not influence the dimensions of the lower anterior face height, as concluded by Nanda (17) who reported that posterior face height and ramal height do not significantly differ between facial types.

\section{Comparison of the Dental Linear Measurements (Den- toalveolar Heights)}

Considering that the dental height increases with growth $(12,18)$, the present study evaluated only the dentoalveolar heights in the phase of maximum spurt of pubertal growth, verifying that, in the incisor area the 3 groups differed in relation to the AUDH measurements and also for the ALDH measurements $(\mathrm{p}=0.002$ and $\mathrm{p}=0.006$ ). For AUDH measurements, significant differences were attributed to the groups with normal and excess lower anterior face height (averages of 27.66 and 29.23, respectively) and for ALDH measurements for the groups with normal and short lower anterior face height (averages of 40.10 and 38.50, respectively). Schendel et al.(2) and Janson et al. (10) observed that all anterior dental heights were larger in the group with 
excessive, and smaller in the group with short lower anterior face height, compared to the normal group. Fields et al. (4) observed that posterior dental heights were larger in the long face type and smaller in the short face type, although the differences in anterior dental height were not significant.

There was a positive correlation among anterior and posterior dentoalveolar heights with the proportion of the facial third, except for the maxillary posterior dentoalveolar height in the group with short lower anterior face height. In spite of the dentoalveolar heights in the group with short lower anterior face height not being smaller than that in the group with normal facial third, the Pearson correlation indicated that dentoalveolar height of the incisors was responsible for the variation of the lower facial third.

\section{Overbite}

In spite of the fact that the studied sample did not consider the vertical trespass of the incisors as a selection criterion, it is important to point out the influence or lack of influence of overbite in facial types. In this investigation, vertical trespass of the incisors was not correlated with the variation of the lower facial height. Bishara and Jakobsen (18) reported that overbite is correlated with the changes in the proportion N-ANS/ $\mathrm{N}-\mathrm{Me}$, during the growth period. Fleming (19) showed a correlation between the lower anterior face height and overbite. On the other hand, Linder-Aronson and Woodside (20) found no correlation between the lower anterior face height and overbite.

In patients with excessive lower anterior face height, the treatment plan without extraction should be concerned with extrusive mechanics such as the incorrect assembly of the accessories, vertical and intermaxillary elastics, and Kloehn extra-oral appliance, used during treatment. These mechanics could provoke dental extrusion and an increase of the dentoalveolar height, the measurement and clockwise rotation of the mandibular plane, and the lower anterior third facial height.

The correct diagnosis of the short lower anterior face height could indicate an etiologic factor, with the objective to modify lower anterior face height. Extrusion forces (construction of the appliance with the accessories positioned more cervically, vertical elastics of intercuspidation and intermaxillary class II or III, Kloehn extra-oral appliance with the outer bow below the inner bow to promote "tip-back" or with the outer bow above the inner bow) may be desirable to improve the vertical dimension in growing individuals with short lower anterior face height.

From the results obtained in this work, it was possible to conclude that: 1) comparing the measurements of the groups with short, normal and excessive lower anterior face height, it was observed that there were significant differences for palatal plane, axial inclinations of the permanent first molars, mandibular length, anterior upper and lower dentoalveolar height; 2) three anatomical parts were responsible for the variation of the lower face height: mandibular length, anterior upper and lower dentoalveolar height. Therefore, these cephalometric measurements may indicate the variation of the lower face height, rather than only the analysis of the proportion of the anterior facial height.

\section{RESUMO}

As dimensões dentoesqueléticas de indivíduos com padrão esquelético de Classe I foram comparadas na puberdade. Oitenta pacientes com maloclusão de Classe I foram selecionados, independente do trespasse vertical dos incisivos (sobremordida). A amostra foi dividida em 3 grupos: com altura facial inferior normal, diminuída e aumentada, baseados na proporção facial. As medidas dentoesqueléticas dos 3 grupos foram comparadas entre si. Nas medidas angulares os resultados mostraram que não houve diferenças na inclinação do plano mandibular. Nas medidas lineares o comprimento mandibular foi significantemente maior no grupo com terço facial diminuído, com correlação positiva nos 3 grupos. As alturas dentoalveolares dos incisivos apresentaram correlação positiva nos 3 grupos em relação ao terço facial inferior, mostrando serem responsáveis pela variação da altura facial inferior.

\section{ACKNOWLEDGEMENTS}

This research was part of the requirement to obtain the title of master in dentistry by Dr. Carla Enoki in the Post Graduate Program in Orthodontics of the Faculty of Dentistry of the Federal University of Rio de Janeiro and was supported by CAPES (Coordenação de Aperfeiçoamento de Pessoal de Nivel Superior).

\section{REFERENCES}

1. Wylie WL, Johnson EL. Rapid evaluation of facial dysplasia in the vertical plane. Angle Orthod 1952;22:165-182.

2. Schendel SA, Eisenfeld J, Bell WH, Epker BN, Mishelevich DJ. The long face syndrome: vertical maxillary excess. Am J Orthod 1976;70:398-408. 
3. Opdebeeck H, Bell WH. The short face syndrome. Am J Orthod 1978;73:499-511.

4. Fields HW, Proffit WR, Nixon WL, Phillips C, Stanek E. Facial pattern differences in long-faced children and adults. Am J Orthod 1984;85:217-223.

5. Scheidman GB, Bell WH, Legan HL, Finn RA, Reisch JS. Cephalometric analysis of dentofacial normals. Am J Orthod 1980;78:404-420.

6. Bishara SE, Jakobsen MA. Longitudinal changes in three normal facial types. Am J Orthod 1985;88:466-502.

7. Tsunori M, Mashita M, Kasai K. Relationship between facial types and tooth and bone characteristics of the mandible obtained by CT scanning. Angle Orthod 1998;68:557-562.

8. Ligthelm-Bakker ASWMR, Wattel E, Uljee IH, Prahl-Andersen B. Vertical growth of the anterior face: a new approach. Am J Orthod Dentofac Orthop 1992;101:509-513.

9. Chua A, Lim JYS, Lubit EC. The effects of extraction versus nonextraction orthodontic treatment on the growth of the lower anterior face height. Am J Orthod Dentofac Orthop 1993;104:361-368.

10. Janson GRP, Metaxas A, Woodside DG. Variation in maxillary and mandibular molar and incisor vertical dimension in 12-yearold subjects with excess, normal, and short lower anterior face height. Am J Orthod Dentofac Orthop 1994;106:409-418.

11. Creekmore TD. Inhibition or stimulation of the vertical growth of the facial complex, its significance to treatment. Angle Orthod
1967;37:285-297.

12. Chang HP, Kinoshita Z, Kawamoto T. A study of the growth changes in facial configuration. Eur J Orthod 1993;15:493-501.

13. Skieller V, Björk A, Linde-Hansen T. Prediction of mandibular growth rotation evaluated from a longitudinal implant sample. Am J Orthod Dentofac Orthop 1984;86:359-370.

14. Lee RS, Daniel FJ, Swartz M, Baumrind S, Korn EL. Assessment of a method for the prediction of mandibular rotation. Am J Orthod Dentofac Orthop 1987;91:395-402.

15. Nanda RS. Growth patterns in subjects with long and short faces. Am. J. Orthod Dentofac Orthop 1990;98:247-258.

16. Opdebeeck H, Bell WH, Eisenfeld J, Mishelevich D. Comparative study between the SFS and LFS rotation as a possible morphogenic mechanism. Am J Orthod 1978;74:509-521.

17. Nanda SK. Patterns of vertical growth in the face. Am J Orthod Dentofac Orthop 1988;93:103-116.

18. Bishara SE, Jakobsen JR. Changes in overbite and face height from 5 to 45 years of age in normal subjects. Angle Orthod 1998;68:209-216.

19. Fleming HB. An investigation of the vertical overbite during the eruption of the permanent dentition. Angle Orthod 1961;31:5362.

20. Linder-Aronson S, Woodside DG. Some craniofacial variables related to small or diminishing lower anterior face height. Swed Dent J 1982;15:131-146. 